\title{
Special Issue: Linguistic diversity, equity and pedagogical innovation in higher education
}

\section{Editors:}

Benjamin Kinsella

Rutgers, the State University of New Jersey

Demet Arpacik \& María Cioè-Peña

Graduate Centre, CUNY, New York, USA

With: Esteban Rodríguez \& Maryann Polesinelli

Text received 26 May 2016, accepted 26 May 2016, final version 28 May 2016 DOI: http://dx.doi.org/10.5565/rev/jt13.674

\section{Editors's Notes:}

This monograph will report on the results of a series of case studies conducted across several campuses of the City University of New York within a university-sponsored project entitled Futures Initiative (FI). The FI project advocates for greater equity and innovation in higher education through several actions, including research and student and teacher development initiatives. In this monograph, the authors of the contributions came together in an interdisciplinary doctoral seminar on educational language policy, which was chosen to take on an active role in the FI project. The seminar was led by Dr. Ofelia García and Dr. Carmina Makar. The issues raised in the seminar, coupled with the goals of the FI project, invited deeper awareness, criticality and increased agency in terms of linguistic diversity, language policies and equity as they were understood and experienced by different populations at the university. The participants in the seminar thus engaged in an innovative pedagogical process of becoming sociolinguistic ethnographers, thereby developing tools and agency to contribute to heightened awareness of salient issues within their local university context and to the potential transformation of language-related injustices through their research.

The invited author for this monograph is Dr. Camina Makar, who was one of the professors guiding the research discussed in the articles. In her contribution, Dr. Makar provides a contextual background to the FI project and discusses the role of multilingualism in higher education policy and pedagogy. She further provides an overview of the methodological approach taken in the different case studies included in the monograph and the relationship between the research conducted and the pedagogical development of the doctoral seminar. Finally, she reflects on some of the implications of this research for the City University of New York and beyond. 
In the next article, Renata Archanjo and Demet Arpacik look at the various platforms that learners from diverse backgrounds created at a voluntarily held Kurdish language class (Kurmanji) in New York. Kurdish, with a long history of forced assimilation and extermination by the nation-states in which Kurds live, has found refuge mainly in exile. In this research study, the authors describe the dynamics within and beyond classroom to gain a deeper understanding of the complex ideologies, power-resistance dichotomy, and identities that learners redefine, reclaim and reconstruct. Findings reveal that participants used the class as a platform to challenge and resist established relations of power, which aim to exterminate Kurdish and to transform the educational space into a space of freedom.

In "The burden of 'nativeness': Four plurilingual student-teachers' stories," Maria Cioè-Peña, Emilee Moore and Luisa Martin Rojo present the narratives of four teacher candidates in which their experiences as multilingual learners and as students training to be bilingual teachers are explored. Cioè-Peña, Moore, and Martin Rojo dutifully discuss the conflict that arises when one's desire to perform like a native speaker becomes a need, ultimately defining one's understanding of what it means to be a successful bilingual teacher.

The fourth article in the special issue, written by Hannah Göppert and Andrea Springith, gives voice to the students, administrators, and staff of Medgar Evers College. The college, which was historically tied to Black Campus Movement, played a central role in Civil Rights Movement. The authors investigate the linguistic and cultural dynamics, which have occurred as as a result of the increase in the diversification of the student body in colleges and universities. The authors indicate that with a commitment to serve its community, a legacy it inherited from the Civil Rights Movement, the college attempts to meet the needs of its increasingly diverse population. Their paper provides insight into the challenges at the intersection of linguistic and racial/ethnic diversification within CUNY's Medgar Evers College.

Next, Stephanie Love, discusses the linguistic ideologies of second-generation bilingual students in one Arabic for Native Speakers/Heritage Learners course. Love problematizes the notions of "heritage speaker" and "native speaker", which she describes as being constructs of a monoglot society. She argues that there is a link between the word "broken Arabic" used frequently by the interviewees and the concept of incomplete acquisition and attrition in SLA research. Calling our attention to the effect of normative ideology on heritage language classrooms in the United States, Love argues for the 
implementation of an approach that emphasizes performativity and respects the diversity of learners.

The final article in this issue also explores issues of identity and how individuals evaluate their own linguistic practices. In "Ideology, access, and status: Spanish-English bilinguals in the foreign-language classroom," Michael Rolland gives voice to heritage speakers enrolled in foreign language courses, a subset of students who have not garnered much attention within the linguistics research community. In his article, Rolland presents the values that these students hold about their own linguistic practices in relation to "the standard" as well as opportunities for change.

The series of articles is then followed by a review of Alexakos' (2015) "Being a teacher | researcher: A primer on doing authentic inquiry research on teaching and learning," reviewed by Nathaly González. As noted by the reviewer, the book serves as a primer for teachers and researchers to engage in inquiry research. That is, Alexakos' book maintains that the dialectic relationship between the teacher and researcher (denoted by the "|" symbol) informs each role, thus facilitating the generation of new knowledge and practices to bridge what has been described as the theory-practice divide. In sum, the book's detailed framework with concrete strategies serves the needs of both expert and non-expert audiences, providing a clear guide to design research in the classroom from the teacher $\mid$ researcher perspective.

And finally, the special issue concludes an in-depth interview with Dr. Ofelia García, led by Benjamin Kinsella. In this interview, García and Kinsella discuss the development of language policy as an interdisciplinary field and how research has informed teaching practices in NYC and beyond. García articulates that globalization and the proliferation of technology has created dynamic language policies, which can no longer be described as simply 'topdown' or 'bottom-up.' Thus, García provides direction for future research on language policy, maintaining that we must consider not only the sustainability, but also the dynamisms of languages in interaction.

Together, this special issue is more than just a collection of case studies on language diversity in higher education. The research and pedagogical model on which it is framed provides an innovative social justice-oriented perspective on linguistic diversity and language policies in higher education, which questions neoliberal understandings of the purely instrumental value of language at universities. 


\section{References}

Alexakos, K. (2015). Being a teacher | researcher: A primer on doing authentic inquiry research on teaching and learning. The Netherlands: Rotterdam. Sense Publishers.

\section{Acknowledgements}

We would like to acknowledge the following people who have not authored articles in this special issue, but who participated in the doctoral seminar that was the genesis of this project, and whose valuable insights and feedback contributed to this monograph reaching fruition: Nicholas Barrington (who contributed to the research described in the article by Göppert and Springirth), Catherine Colleary (who conducted research on the influence of teacher candidates' language background on their educational experience and professional goals), Maryann Polesinelli (who researched legal issues in relation to emergent bilinguals with disabilities in New York education systems and who also is part of the editorial team), Cheryl Olivieri (who researched the role of Brooklyn College within the global political framework and also contributed to formulating the initial proposal for this monograph), Gabrijela Reljic (a visiting researcher from the University of Luxemburg who contributed research on family language policy) and Esteban Rodríguez (who researched Chinese language, ethnicity and the promise of upward mobility at Baruch College and who is also part of the editorial team).

We would especially like to acknowledge two very special professors that are deeply committed to linguistic diversity, equity and pedagogical innovation, Dr. Ofelia García and Dr. Carmina Makar, who drove this project and to whom we dedicate this monograph.

\section{Credits:}

Illustrations for the covers of each issue are designed by students of EINA (Escola de Disseny i Art, Barcelona) studying in the postgraduate course 'Il-lustració Creativa', under the direction of Sonia Pulido, teacher of Illustration for Publishing Media.

\section{Reviewers for Volume 9.2}

The editors would like to thank the following reviewers for their contribution to the preparation of Volume 9.2:

Jaume Batlle Rodríguez (Universitat de Barcelona); Eulàlia Borràs Ribas (Universitat Politècnica de Catalunya); Ruth Breeze (Universitat de Navarra); Natasha Evnitskaya (Universidad Autònoma de Madrid); Lídia Gallego Balsà (Universitat de Lleida); Maria Rosa Garrido Sardà (Université de Fribourg); Janus Mortensen (University of Copenhagen); Luci Nussbaum Capdevila (Universitat Autònoma de Barcelona); Sònia Oliver del Olmo (Universitat Autònoma de Barcelona); Adriana Patiño Santos (University of Southampton); Helena Roquet Pugès (Universitat Internacional de Catalunya); María Sabaté Dalmau (Universitat de Lleida); Josep Soler Carbonell (Stockholm University)

Author's information: Benjamin Kinsella is a $\mathrm{PhD}$ student in the Bilingualism and Second Language Acquisition program at Rutgers, the State University of New Jersey. His line of inquiry explores two interrelated avenues in the field of sociolinguistics: education policy and the increasing Hispanic presence in the New York metropolitan area. Currently, Benjamin is investigating microstructural and macrostructural aspects of oral narratives, examining Spanish language maintenance and intersibling variation among children of Mexican descent in Central New Jersey.

Email: benjamin.kinsella@rutgers.edu

Author's information: María Cioè-Peña is a member of the teaching staff at the City University of New York. She has an undergraduate degree in English and a Master's degree in teaching urban students with disabilities. She is currently pursuing her PhD in the department of Urban Education at the CUNY Graduate Center where she is a Presidential MAGNET Fellow. Her research focuses on bilingual children with disabilities and their 
ability to access multilingual learning spaces within NYC public schools. Her interest are deeply rooted in her experience as a bilingual special education teacher with a focus on language practices and disability awareness within schools and families.

Email: mcp.pena@gmail.com

Author's information: Demet Arpacik is currently a $\mathrm{PhD}$ student in the Urban Education Department at the Graduate Center of CUNY, New York with a concentration in Language, Context, and Culture in Education. She received her M.Ed. in Educational Leadership and Administration from Boston College in 2013. She is currently a member of the teaching staff at Hunter College, New York. She is interested in the Kurdish language policy in Turkey around the issues of nationalism and modernization. Her research interests include multilingual education, minority language rights, critique of national education as well as the Kurdish language movement.

Email: darpacik@gradcenter.cuny.edu

To cite this article:

Kinsella, B., Cioè-Peña, M., \& Arpacik, D. (2016). Special Issue Editors’ Notes: Linguistic diversity, equity and pedagogical innovation in higher education. Bellaterra Journal of Teaching \& Learning Language \& Literature, 9(2), 1-5. DOI: http://dx.doi.org/10.5565/rev/jtl3.674 